\title{
HUBUNGAN PREMENSTRUAL SYNDROME DAN EMOTION FOCUSED COPING PADA SISWI SMP
}

\author{
Correlation Between Premenstrual Syndrome and Emotion Focused Coping in \\ Female Students of Secondary School.
}

\author{
Aris Widiyanto $^{1}$, Asruria Sani Fajriah ${ }^{2}$, Joko Tri Atmojo ${ }^{1}$, Rina Tri Handayani ${ }^{1}$, \\ Santy Irene Putri ${ }^{3}$ \\ ${ }^{1}$ STIKES Mamba’ul 'Ulum Surakarta \\ ${ }^{2}$ IIK Strada Indonesia \\ ${ }^{3}$ Universitas Tribuana Tunggadewi Malang \\ (sanifajriah@gmail.com)
}

\begin{abstract}
ABSTRAK
Latar Belakang: $P M S$ adalah sekumpulan keluhan dan gejala fisik, emosional, dan perilaku yang terjadi pada wanita. Gejala $P M S$ tersebut dapat dinilai sebagai stressor dan penilaian wanita terhadap gejala $P M S$ ini memengaruhi upaya coping untuk menghadapi PMS. Coping yang efektif digunakan seorang wanita untuk menghadapi PMS adalah emotion focused coping, ini disebabkan karena wanita lebih menggunakan emosional daripada logika atau rasio dalam menghadapai stressor karena di dalam tubuh wanita terdapat sistem limbik yang lebih aktif dibandingkan pria. Penelitian ini bertujuan untuk mengetahui hubungan premenstrual syndrome dan emotion focused coping pada siswi SMP.

Metode: Penelitian ini menggunakan desain observasional analitik dengan pendekatan cross sectional. Teknik sampling menggunakan purposive sampling. Besar sampel adalah 62 siswi yang memenuhi kriteria retriksi. Teknik pengumpulan data menggunakan skala kuesioner SPAF (the shortened premenstrual assessment form) dan PMCM (premenstrual coping measure). Teknik analisis data menggunakan korelasi Sprearman.

Hasil: Sebagian besar responden mengalami $P M S$ tingkat sangat ringan yaitu sebanyak 34 responden $(54,84 \%)$ dan sebagian besar skor $E F C$ antara 43-85 yaitu 41 responden $(66,13 \%)$. Berdasarkan hasil analisis data menggunakan uji statistik Spearman diperoleh nilai significancy $0,032(p<0,05)$ dengan koefisien korelasi sebesar 0,272 menunjukkan bahwa kekuatan korelasi lemah dengan arah korelasi positif.
\end{abstract}

Simpulan: Terdapat hubungan yang bermakna antara premenstrual syndrome dan emotion focused coping pada siswi SMP.

Kata Kunci: premenstrual syndrome, emotion focused coping 


\begin{abstract}
Background: PMS condition frequently experienced by women is physical and psychological symptoms. PMS symptoms can be assessed as stressor and estimation of women about this PMS symptoms coping affect to face PMS. Emotion focused coping is the effective coping was used by a woman to face PMS because that women more use emotional than logic or ratio to face stressor is caused that the inside of women's body there is a limbic system that more active than men. The objective of this research is to investigate the correlation between premenstrual syndrome and emotion focused coping among female students of secondary school.

Method: This research used observational design by using approachment cross sectional. Sample was 62 female students that had been selected with criteria of restriction. Data was collected by using SPAF (shortened premenstrual assessment form) scale and PMCM (premenstrual coping measure) scale. The data was analyzed by using Spearman's correlation.

Result: In majority, 34 respondents $(54.84 \%)$ and most of EFC score between 4385 is 41 respondents $(66.13 \%)$, based on the data analysis by using Spearman's statistical test, a significance value of $0.03(\mathrm{p}<0.05)$ and coefficient of correlation of 0.272 that shown the strength of weak correlation with a positive correclition.

Conclusion: The premenstrual syndrome had a correlation with the emotion focused coping in female students of secondary school.
\end{abstract}

Key words: premenstrual syndrome, emotion focused coping

\title{
PENDAHULUAN
}

Gejala $P M S$ dapat memengaruhi fisik dan mental selama periode $P M S$ (Rice, 2013). Individu perlu melalui proses dalam menyelesaikan situasi yang stressfull atau disebut dengan coping (Khoiroh, 2013). Coping merupakan upaya seseorang untuk menghadapi tekanan yang ditimbulkan masalah yang dihadapinya, dengan cara melakukan perubahan perilaku agar mendapatkan rasa aman dan nyaman dalam dirinya (Urbayatun, 2017).

Wanita cenderung menggunakan emosional sehingga jarang menggunakan logika atau rasio dalam menghadapi sumber stress (Mustafa, 2012). Umumnya strategi coping yang dapat dilakukan oleh seseorang untuk menghadapi stress adalah problem focused coping dan emotion focused coping. Problem focused coping adalah teknik mengatasi stress dengan menyelesaikan masalah secara langsung dan dapat bersumber dari lingkungan maupun diri sendiri. Sedangkan emotion focused coping adalah strategi penyelesaian masalah dengan berorientasi pada emosi untuk meredakan dan mengelola stress yang muncul akibat interaksi individu dengan lingkungannya (Bakhtiar dan Asriani, 2015)

Berdasarkan studi pendahuluan yang dilakukan tanggal 27 November 2015 pada siswi SMP Negeri 16 Surakarta, dari 10 siswa terdapat 9 siswa yang mengeluhkan gejala $P M S$ dan hanya 1 yang tidak mengalami gejala $P M S$. Gejala 
umum yang dikeluhkan adalah nyeri perut, tubuh pegal-pegal, letih, pusing, perasaan lebih sensitif seperti mudah emosi, mudah menangis, dan nafsu makan berkurang. Sebagian besar siswi mengaku kesulitan menyesuaikan diri dengan mudah, sehingga pengendalian diri para siswi saat menstruasi juga kurang.

Penelitian sejenis oleh Mustafa (2012), berjudul "Emotion Focused Coping dan Penyesuaian Diri terhadap Sindrom Premenstruasi pada Wanita Bekerja di Mulia Toserba Bantul" menunjukkan bahwa terdapat hubungan signifikan antara emotion focused coping dan penyesuaian diri positif pada wanita bekerja. Artinya wanita bekerja yang mengalami PMS melakukan emotion focused coping karena kondisi tersebut di luar kontrolnya sehingga akan memberikan sumbangan efektif terhadap penyesuaian diri positif.

Berdasarkan beberapa uraian di atas, peneliti tertarik untuk melakukan penelitian tentang "Hubungan Premenstrual Syndrome dan Emotion Focused Coping pada Siswi SMP”.

\section{METODE PENELITIAN}

Penelitian ini menggunakan desain penelitian observasional analitik dengan pendekatan cross sectional, dimana peneliti mencoba untuk mencari hubungan premenstrual syndrome dan emotion focused coping pada siswi SMP.

Populasi penelitian ini adalah semua siswi kelas VII SMPN 16 Surakarta. Sampel pada penelitian ini adalah siswi yang sudah mengalami menstruasi. Teknik sampling yang digunakan pada penelitian ini adalah Purposive Sampling. Peneliti mengambil semua siswi kelas VII SMPN 16 Surakarta yang sudah mengalami menstruasi sebanyak 62 responden.

Peneliti menggunakan instrumen kuesioner tertutup untuk mengukur skala premenstrual syndrome dan skala emotion focused coping. Pengumpulan data dilakukan dengan mengurus perizinan penelitian, membuat daftar hadir responden, mendatangi SMPN 16 Surakarta sesuai jadwal yang ditentukan oleh peneliti berdasarkan jadwal PMS responden yaitu tanggal 5 Februari 2020 s.d. 20 Februari 2020, mendatangi dan membagikan kuesioner kepada responden dan menjelaskan tujuan penelitian. Selanjutnya, meminta responden mengisi kuesioner mengenai PMS dan EFC sesuai kondisi yang dialami responden.

Pengolahan data dilakukan dengan editing (pemeriksaan data), coding (pemberian kode), data entry (pemasukan data), dan tabulating (penyusunan data).

Analisis data berupa analisis univariat yaitu menganalisis secara deskriptif masing-masing variabel dengan menghitung distribusi dan menampilkan tabel karakteristik serta bivariat untuk mengetahui hubungan dua variabel yaitu $P M S$ dan EFC dengan menggunakan uji statistik korelasi Sprearman menggunakan program komputer SPSS for Windows versi 16.0. 


\section{HASIL DAN PEMBAHASAN}

\section{Hasil}

\section{A. Analisis Univariat}

Tabel 1. Karakteristik Siswi SMP

\begin{tabular}{lcc}
\hline \multicolumn{1}{c}{ Jenis Data } & f & \% \\
\hline Usia & & \\
11 tahun & 1 & 1,61 \\
12 tahun & 30 & 48,39 \\
13 tahun & 31 & 50 \\
Total & $\mathbf{6 2}$ & $\mathbf{1 0 0}$ \\
Usia Menarche & & \\
9 tahun & 1 & 1,61 \\
10 tahun & 5 & 8,07 \\
11 tahun & 18 & 29,03 \\
12 tahun & 38 & 61,29 \\
Total & $\mathbf{6 2}$ & $\mathbf{1 0 0}$ \\
\hline
\end{tabular}

Sumber: Data Primer, 2016

Dari tabel di atas, usia siswi SMP terbanyak adalah 13 tahun sebanyak 31 responden $(50 \%)$. Usia menarche terbanyak 12 tahun sebanyak 38 responden $(61,29 \%)$.

\section{B. Analisis Bivariat}

Tabel 2. Distribusi Frekuensi Karakteristik Tingkat Premenstrual Syndrome

\begin{tabular}{lcc}
\multicolumn{1}{c}{$(P M S)$} & & \\
\hline \multicolumn{1}{c}{ Jenis Data } & f & Presentase (\%) \\
\hline Tingkat $P \boldsymbol{M S}$ & 16 & 25,81 \\
Normal & 34 & 54,84 \\
Sangat ringan & 7 & 11,29 \\
Ringan & 4 & 6,45 \\
Sedang & 1 & 1,61 \\
Berat & 0 & 0 \\
Sangat Berat & $\mathbf{6 2}$ & $\mathbf{1 0 0}$ \\
Total & &
\end{tabular}

Tabel di atas menunjukkan bahwa sebagian besar siswi SMP memiliki tingkat $P M S$ sangat ringan sebanyak 34 responden $(54,84 \%)$.

Tabel 3. Distribusi Frekuensi Karakteristik Hasil Skor Emotion Focused Coping

\begin{tabular}{ccc}
$(E F C)$ & f & \\
\hline Jenis Data & & Presentase (\%) \\
\hline Skor $\boldsymbol{E F C}$ & 14 & 22,58 \\
$0-42$ & 41 & 66,13 \\
$43-85$ & 7 & 11,29 \\
$86-128$ & $\mathbf{6 2}$ & $\mathbf{1 0 0}$ \\
Total & &
\end{tabular}

Sumber: Data Primer, 2016 
Tabel di atas menunjukkan bahwa sebagian besar siswi SMP memiliki skor $E F C$ antara 43-85 yaitu sebanyak 41 responden $(66,13 \%)$. Responden dengan skor $E F C$ antara 86-128 sebanyak 7 responden $(11,29 \%)$.

Tabel 4. Tabulasi Silang Premenstrual Syndrome (PMS) dan Emotion Focused Coping (EFC) pada Siswi SMP

\begin{tabular}{lcccccccc}
\multicolumn{1}{c}{$\boldsymbol{P M S}$} & \multicolumn{1}{c}{$\mathbf{0 - 4 2}$} & \multicolumn{2}{c}{$\mathbf{4 3 - 8 5}$} & \multicolumn{2}{c}{$\mathbf{8 6 - 1 2 8}$} & \multicolumn{2}{c}{ Total } \\
& $\mathbf{F}$ & $\mathbf{\%}$ & $\mathbf{F}$ & $\mathbf{\%}$ & $\mathbf{F}$ & $\mathbf{\%}$ & $\mathbf{F}$ & $\mathbf{\%}$ \\
\hline Normal & 4 & 6,45 & 11 & 17,74 & 1 & 1,61 & 16 & 25,81 \\
Sangat & 9 & 14,52 & 20 & 32,26 & 5 & 8,07 & 34 & 54,84 \\
Ringan & & 1,61 & 6 & 9,68 & 0 & 0 & 7 & 11,29 \\
Ringan & 1 & 0 & 3 & 4,84 & 1 & 1,61 & 4 & 6,45 \\
Sedang & 0 & 0 & 1 & 1,61 & 0 & 0 & 1 & 1,61 \\
Berat & 0 & 0 & 0 & 0 & 0 & 0 & 0 & 0 \\
Sangat & 0 & 0 & 0 & & & & \\
Berat & 14 & 22,58 & 41 & 66,13 & 7 & 11,29 & 62 & 100 \\
\hline Total & 14
\end{tabular}

Sumber: Data Primer, 2016

Tabel di atas menunjukkan sebagian besar responden yang mengalami $P M S$ tingkat normal, sangat ringan, ringan, sedang, dan berat memiliki skor $E F C$ antara 43-85 yaitu sebanyak 11 responden (17,74\%); 20 responden $(32,26 \%) ; 6$ responden $(9,68 \%)$; 3 responden $(4,84 \%)$; dan 1 responden $(1,61 \%)$, hal ini menunjukkan bahwa skor EFC responden antara 43-85 yaitu sebanyak 41 responden $(66,13 \%)$. Berdasarkan hasil penelitian ditemukan responden dengan skor EFC antara 86-128 sebagian besar dilakukan pada responden yang memiliki tingkat $P M S$ sangat ringan yaitu sebanyak 5 responden $(8,07 \%)$, sedangkan responden dengan tingkat $P M S$ berat memiliki skor $E F C$ 43-85 yaitu 1 responden $(1,61 \%)$.

Analisis data menggunakan uji statistik SPSS for Windows 16.0 dengan uji Spearman didapatkan hasil $p=0,032(p<0,05)$ yang menunjukkan bahwa korelasi antara premenstrual syndrome dan emotion focused coping adalah bermakna dengan koefisien korelasi sebesar $0,272(0,2 \leq \mathrm{r}<0,4)$ yang menunjukkan kekuatan korelasi lemah dengan arah korelasi positif.

\section{Pembahasan}

Hasil penelitian terhadap 62 responden, diperoleh data sebagian besar responden berusia 13 tahun sebanyak 31 responden (50\%) dan usia menarche sebagian besar responden usia 12 tahun berjumlah 38 responden $(61,29 \%)$. Hasil penelitian ini sejalan dengan penelitian Hamella (2014) tentang Hubungan Antara Tingkat Pengetahuan, Usia Menarche, Lama Menstruasi dan Riwayat Keluarga Dengan Kejadian Dismenore pada Siswi di SMPN 2 Kartasura Kabupaten Sukoharjo yang menunjukkan bahwa usia menarche responden terbanyak $\leq 12$ tahun $(78,3 \%)$. 
Berdasarkan hasil penelitian ini sebagian besar responden mengalami tingkat $P M S$ sangat ringan sebanyak 34 responden $(54,84 \%)$ dan satu responden $(1,61 \%)$ yang mengalami tingkat $P M S$ berat. Hal ini disebabkan $P M S$ merupakan gejala umum yang dialami oleh sebagian besar wanita usia reproduksi.

Diduga, hormon prostaglandin menyebabkan otot-otot uterus berkontraksi yang berlebihan atau sensitif terhadap hormon prostaglandin yang dibentuk oleh asam lemak tak jenuh yang disintesis oleh seluruh sel di dalam tubuh. Pada saat level hormon meningkat dan menurun selama siklus menstruasi, perempuan dapat mengalami perubahan fisik maupun emosional (Priyatna, 2009).

Gangguan fisik yang dirasakan akibat perubahan ini adalah cepat lelah, jerawat, sakit kepala, sakit punggung, sakit perut bagian bawah, nyeri payudara, perubahan nafsu makan, dan sering merasa lapar (Toruan, 2014).

Menurut Ratikasari (2015), seorang wanita akan lebih mudah menderita PMS apabila lebih peka terhadap perubahan psikologis, khususnya stress (Michel dan Bonnet, 2014).

Berdasarkan hasil uji statistik SPSS 16.0 for Windows dengan uji Spearman didapatkan nilai significancy $0,032(p<0,05)$ yang menunjukkan bahwa korelasi antara premenstrual syndrome dan emotion focused coping adalah bermakna dengan koefisien korelasi sebesar 0,272 menunjukkan bahwa kekuatan korelasi lemah dengan arah korelasi positif yang artinya jika skor $P M S$ tinggi maka skor EFC juga akan tinggi.

Penelitian ini sesuai dengan penelitian sebelumnya oleh Mustafa (2012) tentang "Emotion Focused Coping dan Penyesuaian Diri terhadap Sindrom Premenstruasi pada Wanita Bekerja di Mulia Toserba bantul" menunjukkan terdapat sumbangan efektif dari emotion focused coping terhadap penyesuaian diri positif sebesar $13,6 \%$, artinya emotion focused coping yang mempunyai andil dalam pembentukan penyesuaian diri positif terhadap $P M S$ pada pramuniaga wanita di Mulia Toserba Bantul.

\section{SIMPULAN DAN SARAN}

\section{Simpulan}

Berdasarkan hasil penelitian dan pembahasan yang telah diuraikan sebelumnya tentang hubungan antara Premenstrual Syndrome (PMS) dan Emotion Focused Coping pada Siswi SMP bahwa terdapat hubungan yang bermakna antara Premenstrual Syndrome dan Emotion Focused Coping pada siswi SMP dengan nilai signifikansi sebesar 0,032 $(p<0,05)$ dengan koefisien korelasi sebesar 0,272 $(0,2 \leq \mathrm{r}<0,4)$ yang menunjukkan kekuatan korelasi lemah dengan arah korelasi positif yang menunjukkan semakin tinggi tingkat $P M S$ responden, maka semakin tinggi skor $E F C$ responden.

\section{Saran}

Diharapkan siswa SMP dapat meningkatkan kemampuan pengendalian dirinya terutama dalam hal emotion focused coping saat menghadapi gejala-gejala $P M S$ dengan cara menghindari situasi, orang, percakapan maupun pikiran-pikiran 
yang dapat menimbulkan distress serta meningkatkan kesadaran dan penerimaan terhadap adanya perubahan fisik dan psikis saat $P M S$. melakukan aktivitas yang membuat rasa nyaman. Diharapkan remaja dapat meningkatkan pengetahuannya tentang kesahatan reproduksi remaja terutama tentang PMS (Premenstrual Syndrome) dengan memanfaatkan kemajuan teknologi yang ada untuk mendapatkan informasi tentang kesehatan reproduksi. Bagi peneliti selanjutnya diharapkan dapat mengendalikan faktor lain yang memengaruhi PMS seperti nutrisi, lifestyle, dan aktifitas fisik, serta faktor yang memengaruhi coping baik faktor internal maupun faktor eksternal serta faktor spesifik lain yaitu ujian terstandar dari sekolah yang dapat menyebabkan stress.

\section{DAFTAR PUSTAKA}

Bakhtiar MI, Asriani (2015). Efektivitas strategi problem focused coping dan emotion focused coping dalam meningkatkan pengelolaan stress siswa di SMA Negeri 1 Barru. Jurnal Ilmu Pendidikan, Psikologi, Bimbingan, dan Konseling. 5(2). Diakses dari https://media.neliti.com/media/publications/41228-ID-efektivitas-strategi-problem-focused-coping-dan-emotion-focused-coping-dalam-men.pdf

Hamella, C (2014). Hubungan antara tingkat pengetahuan, usia menarche, lama menstruasi dan riwayat keluarga dengan kejadian dismenore pada siswi di smpn 2 kartasura kabupaten Sukoharjo. Surakarta: Fakultas Ilmu Kesehatan Universitas Muhammadiyah Surakarta. Diakses dari http://eprints.ums.ac.id130517/2/02. ARTIKEL_PUBLIKASI.pdf

Khoiroh Q (2013). Hubungan strategi coping dengan tingkat premenstrual syndrome pada mahasiswi fakultas psikologi Universitas Islam Negeri Maulana Malik Ibrahim Malang. Universitas Islam Negeri Maulana Malik Ibrahim Malang. Diakses dari https://core.ac.uk/download/pdf/34004189.p$\underline{\text { df }}$

Michel CL, Bonnet X (2014). Effect of a brief stress on progesterone plasma levels in pregnant and non-pregnant guinea pigs. Animal Biology. 64(1): 19-29. doi https://doi.org/10.1163/15707563-00002428

Mustafa (2012). Emotion focused coping dan penyesuaian diri terhadap sindrom premenstruasi pada wanita bekerja di mulia toserba bantul. Yogyakarta: Universitas Islam Negeri Sunan Kalijaga Yogyakarta. Diakses dari http://digilib.uin-suka.ac.id/10861/1/BAB\%20I,\%20V,\%20DAFTAR\%2OPUSTAKA.pdf.

Rice L (2013). Food remidies. premenstrual syndrome. U. S. A: F+W Media.

Toruan PL (2014). Weight loss; kiat langsing seumur hidup. Jakarta Selatan: Transmedia. p: 73.

Urbayatun S (2017). Atasi stress dengan manajemen coping. Warta Utama UAD. Diakses dari https://uad.ac.id/id/atasi-stres-dengan-manajemen-coping/ 